\title{
磷脂類對於組織作用的研究“
}

\author{
馬 文 昭
}

（北京医学院）

人体組織中各种細胞的構浩成分，基本上都 可以分第兩類: 一類是一切細胞所共有的基本結 如細胞膜、細胞核和綫粒体 (在一般組織学 科書中，高基氏器也包括在內，但作者根據过 去的研究, 認篇含有大量磷脂類的高基氏器是由 傿垃与由核排泄出來的核質化合之後分解而形成 的, 因之, 它不能作第細胞的基本結構看待), 另 一頝構造成分是各种細胞所特有的, 如動物澱粉、 分泌顆粒、脂滴、色素等。根掉許多实驗材料示 明: 各种不同細胞內的特殊成分可能是由細胞所 共有的基本結構行化而成的。如哺乳動物的紅血 球，在母細胞階段是有核的，細胞質中並含有多 量的綫粒体，但血色素很少或完全不見，到成熟 的䉺血球，核和粒消泆，所見者只是一团血紅 叕白。

依據钎多化学家和組織学家的見解, 磷脂類 或磷脂与蛋白質的化合物存在於一切細胞的共有 粘構中。

因此，作者推測: 如果供給机体充分的磷脂 矮, 可能加强机体对脂的同化作用, 而且可能 由之而增强細胞的机能, 而这方面的影响, 是可 以从梱胞基本結構的焚化上看出來的。撶此，作. 者進行了多年的“磷脂類对組織作用”的研究。

作者會經覌察到慢性嗎啡中垡者（或雅片跓

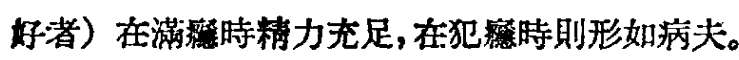
作者利用慢性嗎啡中毒的白鼠進行了研究, 狆現 战驗白鼠有如下的週期性的継化:

一、犯稳期: 白鼠所顯徽狀黨萎糜不振, 不 思飲食, 此時細胞內的基本絬椿 㝤弱, 綫粒诚 少。

二、㴖期: 白毁甚活潑, 病態完全消失。 此洔細胞內的基本結構完好, 緢粒㙕多。

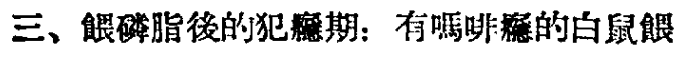

以磷脂, 同時供給常量黛啡使之滿愁, 过 6 日停 供嗎啡，停供洔不㙷任何顯著的病徵。过 216 日 撿柰細胞內基本結棒，細胞核及螕粒等都正常。

綜合上迌三种現像，可以推知磷脂颣有使細 胞基本結構堆强的作肘。

最近五年來，作者研究丁磷脂颣对於表皮組

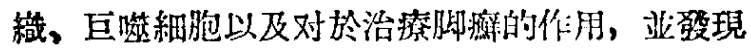
磔脂類能使血色素㙷著㙁加。

在这些研究中所应用的磷脂類是德國出品的 粗慗橫豆卵磷脂，其中重要化学成分: 的含卵磷 脂 $3 / 4$, 腦磷脂不足 $1 / 4$, 耐經磷脂微量。使用時或 口服, 或局部染抹。来筧用純焦的畉磷脂或純製 的腦磷脂進行过实驗。

現在分别叙述其研究方法与結果如下:

一 局部䔦察: 创括研究磷脂類对表皮組織 的作用，对脚摭的效应和对表皮下結䋨組織巨噬 細胞的作用。

（甲）研究方法：探用局部泾抹的方法。白 鼠的右耳每日症抹磷脂一次, 持續三至四星期。 左耳同樣用手抹擦, 但不用磷脂, 所有的組織標 本在整顯微鏡切片及染色过程中都是平行处理 的。

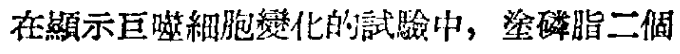
月後，先用台盤藍活体染色。拄隔一日注射 $1 \%$ 台盤藍水溶液一次, 其注射五次。年次用量是矮 公斤体诅 $5 c c$ 。在每次注射後的次日取標本一 次, 另在停止注射後十日取末次標本。这槏, 藉 巨噬細胞固有的吞㗪能力即可检查其在生活㭙的 狀態。

（乙）檢查結果: 若將塗磷脂類櫒本与对照

- 本交是作者五年來在这方面的工作的總赤。诃 於 1955 年 6 月 8 日在中國科学院学部成立大公分組会

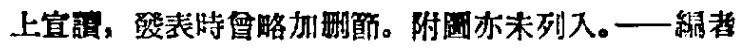


的標本相互比較, 即可看出:

（1）磷脂類对表皮的作用: 在涂磷脂類的 標本上，裴汝細胞的核及核仁增大；細胞体皘增 大, 胞膜着色也格外顯著。由深愿向淺層檢查, 可 見实驗標本生發層細胞內的綫粒及高基氏器遠較 对照標本篇多。細胞內此种結構忩向淺愿忩少。 到粒層則見細胞內充滿了大而透明的角罂層顆 粒; 顆粒的數量, 实驗標本亦比对照標本第多。 表皮染一個時期磷脂類以後, 就增厚很多, 这是由於下述各种現像綜合的結果: 首先是由於 細胞層數的增多，由基底層到粒層可以有 $5-8$ 層 細胞。对炤者只有 $2-3$ 層。实驗標本的粒層也 有 2-3 層, 比对照者多 1-2 倍了透明層和角 質層不易分辨層數，但較对㷊者厚度增加很多。 第二，是由於細胞体棈的增大。实驗標本的基底 細胞成䍃高柱狀, 比对照者高一倍, ‘束層細胞也 顯著增大。第三點是由於磷脂類的处理，使表皮 絊胞間的間陌援大了。实驗標本上表皮䊂層和基 底層的細胞間㭞顯著控大，相互貫通，直到基底 膜。細胞䦭隙的摭大对於上皮細胞与体液間的物 質交換可能起有利作用。

在实驗標本上表皮內可見到很多白血球。有 時白血球在粒層的上面集合成团或成層。这种現 管在对照的標本上是看不到的。

（2）由以上观察絬果，推想磷脂類在臨休 上用於葉些皮店满可能会有適当效果，因此曾用

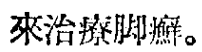

实驗方法: 初步迭擇脚痽患者 47 人(包括作 者在內。有一部分病人經本院附闽医院皮虚科检 查)。確定渗斷後，每日叙磷脂於患处, 早晚各一 次，如是持續三崖期。

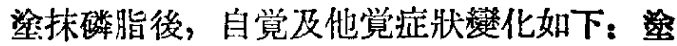

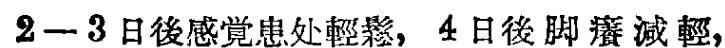

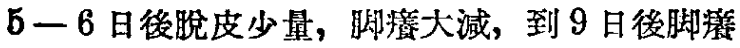
完全停止，瞈皮更多，到 3 星期時表皮角質層眖

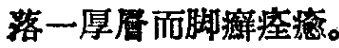

根據此 47 例的調查, 結果全部痊㴰。

（3）在鬼耳盗磷脂後皮下 巨噬細胞的数 化: 依標本取材時間之前後，依次叙述：在第二 次所取（第二次注射台盤藍的次日所取）標本上 可見: 实驗組皮下組織內含台盤藍細胞的數目較 多, 胞体較大, 所含台盤藍顆粒也多。在对照組,
則含台盤蓝細胞的数目較少，胞体較小，所含的 台盤藍顆粒也較少。

在第四第五次所取的標本上, 若將实驗組標 本与对照組標本对比，即可看出实驗組巨噬細胞 的數目增多得很顯著，胞体增大，含台盤藍量也 很多。从細胞的形狀和其所合台盤 $\mathrm{E}_{\mathrm{i}}$ 消化的程 度, 可將細胞分成四种: 一是長梭形的静止細胞,

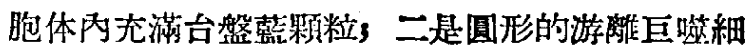
胞，台盤藍顆粒在其体內已有一部分涓化成褐色 顆粒; 三是無定形的活動力最强的巨筑細胞, 胞 內的台盤藍顆粒幾乎完全消化成棕色沦狀; 四是 多核巨紬胞的出現, 其胞內也含有大量台盤葲瀬 粒。在此同一時期內对照組的標本上巨噬細胞踓 比第二次所取標本增多，但不及实驗組，其細胞 內台盤藍增加了，而細胞大牛是松形或分枝的靜 止細胞。

在最後一次所取的標本上，实驗組与对照組 巨噬細胞數目差不多，相应地都比以前減少了， 但在实驗組巨噬細胞內的台盤藍大部被消化成第 棕色泡狀，細胞幾乎全是游離細胞。而对照組的 巨㗪細胞內台盤藍还是深色大塊，細胞仍呈靜止 狀。

这些覌察表明: 一、台盤監在体內增加時, 巨鈭細胞的數目和吞噬能力相应地隨之增加，在 实驗組比对照組增加得更第明顯，其吞㗪能力更 强。二、台盤藍在体队減少時, 巨噬細胞相应地 減少, 实驗組巨筮細胞消化異物的能力較对照組 篇强。

以上，用磷脂類作用於局部的覌察証明了磷 脂類对於表皮組織和皮下巨噬細胞有增强其結棈 和提高其生活活動的作用。

二 整體觀察，作者曾經观察到服磷脂後白 血球內的綫粒和高基氏器均增大增多，白血球的 運動能力也加强。推而及於磷脂 对紅血球的作 用，因此文作了磷脂類对血色素的影响的研究。

方法: 加試驗的 12 人，每人每日口服 脂 3 次，每次 15-20 克，持續 3-4 週。在試验 前，检查血紅蛋白的量並計算紅、白血球的数 目。

結果: 服用磷脂前血紅蛋白平㚬篇 14.3克， 服三星期後第 17.7 克，平均增加 3.4 克。至於和 白血球的數目則無㙷著的改䛓。
6 月号
科学通報 


\section{讨 销}

一、磁脂類有使動物細胞堆强和細胞內基本 粘構（綫粒体及核等）行化物堆多的作用:

从上所求，可以看出磷脂類有使細胞基本結 構增强的作用, 同時这作用也表現在細胞內各种 行化物的形成上。局部鉒磷脂類後, 細胞体皘、 細胞核及核仁的体積都增大, 細胞內綫粒体和高 基氏器堆多; 同時又覌察到血紅蛋白在服磷脂後 增加以及表皮粒屏細胞內唀明角質顆粒增加的現 象。

閵於血紅蛋白的增加方面, 苏联施釷别爾 格、希明列爾和納烏莫娃在研究各种營养物对茠

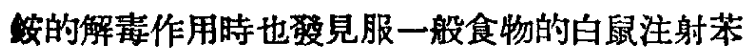
船後, 血紅蛋白比对照動物的降低很多, 紅血球 也有降低的偭向，而服附加率磷脂食物的白鼠， 在注射笨鉸後血紅蛋白的量則与对照的動物相 同，大部白鼠的紅血球數目也都正常。紅血球愫 生血紅蛋白能力的堭加, 可能是由於紅血球母細 胞內部結構的增强。卵磷脂能使哺乳動物別种細 胞的基本結構增强, 細胞的功能地增進, 紅血球

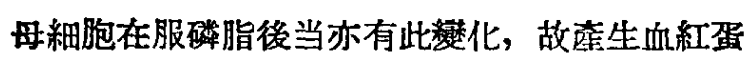
白之能力亦可坦强。

至於表皮粒展細胞內的透明角買颗粒的燴加 進一步即形成表皮最外的角質首; 粒層細胞內顆

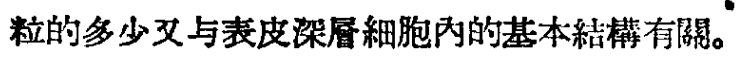

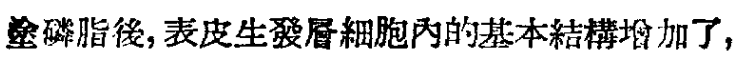

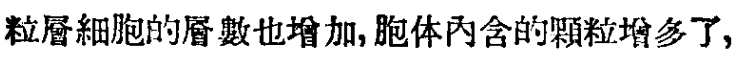
顆粒地增大。这表明塗磷脂後, 由於細胞內基本 桔構的增多, 由其形成的產物也就隨之增多。

二、磷脂類有使細胞生活机能增强的可能。

1. 服磷脂類後，杠血球的數目雖無顯著戀化， 但所含的血紅蛋白增多了。血紅蛋白在呼吸中起 更要作用，血紅蛋白的增加当可促使組織的新陳 代謝更超旺盛。

2. 瓷磷脂類後，表皮各展增厚，粒首的增厚 可能産生角黄居的坦 厚, 使皮有的保護功能增 强。

3. 皮下巨噬細胞, 在向体內注射台盤藍以後 活動能力相应地增强，在塗磷脂後这种反应格外 明影，巨喍和胞數目㘿加更多，細胞亦多屬於活 動型, 㤁些消化台盤藍的能力更强。在停止注射
台盤孯以後, 实騟与对照組標本上的巨噬細胞俱 都诚少。这一點說明磷脂類的作用是使巨检細胞 的活動在異物侵入的情况下更加增强, 異物消诚 時不諭实驗或对照標本巨噬細胞又都恢復常態。 如此, 則磷脂類所引起的是生理性的反应, 而非 病理現象。

4. 磷脂類能㙁强組織的生理机能, 在祝稔就 “磷脂類对於蜼蜍心臟的作用”各篇論交裹也得到 了証明。在这些論文中示明“大豆磷脂的加入確 可使因長期灌流而衰弱的心腧恢復其心室的收樎 能力”“在無銛任氏液中，離体蟭蜍心䁃搏動停止， 某些磷脂和皇類可以使心藏搏動烣復，业維持挠 小時。有效的磷脂篇大豆磷脂、粗製彩蛋磷脂及其

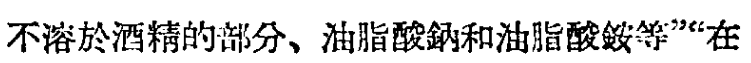
高鐧抑制的心淽, 大豆磷脂与油脂酸政和血清有

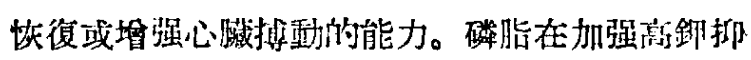
制的机械反应同時, 亦加强心践的動作霓流。”

三、磷脂類使細胞增多的作用, 是生理狀態

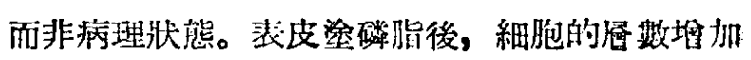
到一定程度即停止, 有的動物羕日染磷脂持維二 年多, 其表皮細胞所增的數目与涂磷脂僅一储月 者無暴。在結䋨組織內巨噬細胞反应的綎化, 已 欲朋磷脂類的作用是生理性的, 与磷脂類对与裴 皮的作用是互相印証的。

这裏需要加以說明的是，使表皮增厚的作用 並非限於磷脂類, 其他如化学性或机械性刺湤、 炎症与腫㨨等，也都有使上皮增生的變化。F.S.

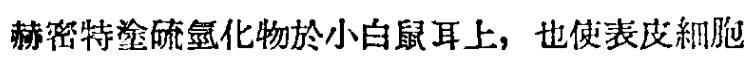
增多。瀝毒且可引起表皮生癌。在我倾進行的实 驗中無論局部采抹或口服或靜脈注射磷䑚, 踓持

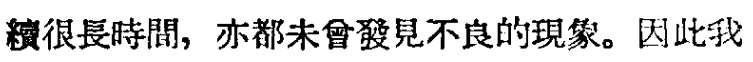

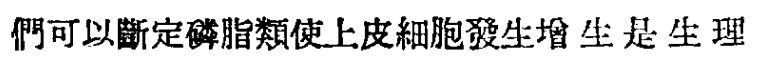
狀態。

\section{結 铪}

本文概括了最近五 年來作者 閵於“磷脂颣对 於組織的作用”方面關於血紅蛋白買高、荠皮細胞 增生、臨床沿療脚游、皮下巨噬細胞忝噬、泞化 罣强等方面的研究(1)，得出結諭如下:

1. 磷脂類能使細胞結構增强: 例如細胞体程 增大、細胞核及核仁㙁大、綫粘買多。

2. 磷脂数能使細胞繁殖犊强：如表皮細胞及 
皮下E噬細胞的數目增多。

3.磷脂類能使細胞功能增强: 如血紅 蛋白的 增高; 表皮粒屏細胞內的透明角睤顆粒大而且 多; 皮下巨噬細胞吞㗪台盤藍顆粒的增多, 消化 能力的增强。

(1)1.磷脂類对於組織的作用一、对表皮的作用, 中
華新医学報，1953，第 3 夋，第10期。

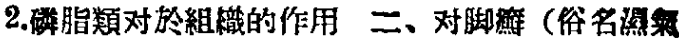

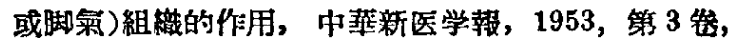
第10期。

3.磷脂類对於組樴的作用 III、对巨筮細胞的伊 用, 解剖学報, 1953 , 第 1 卷, 第 1 期。

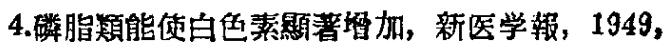
第 1 然，第 2 期。

\title{
家蛪混精雜交的新資料
}

\author{
殷秋松 㢦 琦

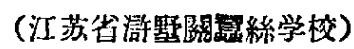

苏联斯特尼可夫教授从受精选擇性的理諭基 碟出發，做了家学重複交配的試驗，用三個雄蛾 的精子, 使一個雌蛾受精, 結果比單 交一雄蛾

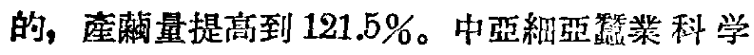
研究所实驗䧳蛾三重交配，次代篦的生命力超过

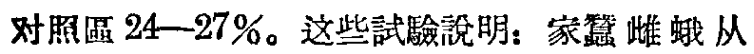
二個乃至三個雄蛾的混合精子中选擇受精，对捉 高後代的生命力上是有实際意義的。

中國科学院实驗生物研究所朱洗先生等會从 事家篮混精雜交的工作（“科学通報”1954 年3月
号, “实驗生物学報”，第 4 突，第 1 期, 1954年)。 我校在 1954 年亦會就家篦混精雜交做了蟣 項 实 驗, 獲得下列結果。

\section{一 家畫受精的選擇性表現}

实驗材料：母体，中 112 姬（然斑紋，白血， 白藏。）父体，I. 中 112 姬。II. 褐尉（褐国斑，白

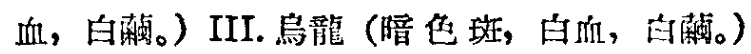

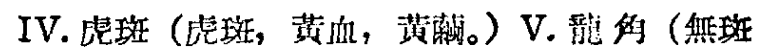

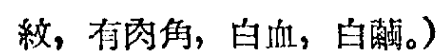

表 一

雜交型式

中 112 姬 $\times$ 中 112 姬

$\times$ 褐圆 $\times$ 虎斑

中 112 姬 $\times$ 鳥龍 $\times$ 中 112

姬 $\times$ 蝎圆

中 112 姬 $\times$ 褐圆 $\times$ 能角

$x$ 中 112 姬

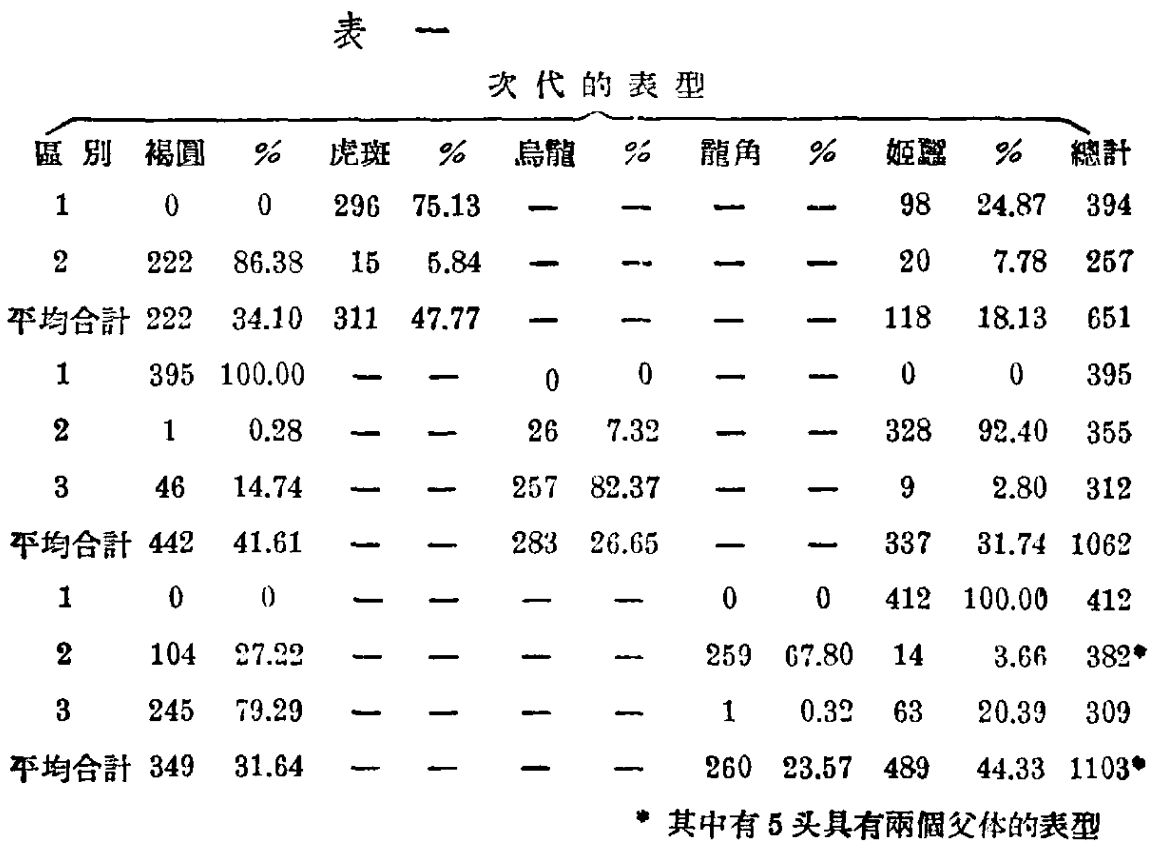

6 月号

科学通報 